\title{
The Action of Antibiotics on Indole Synthesis by Cell Suspensions of Escherichia coli
}

\author{
BY F. GIBSON, BARBARA McDOUGALL, MARJORIE J. JONES \\ AND H. TELTSCHER
}

Bacteriology School, University of Melbourne, Australia

\begin{abstract}
SUMMARY: Indole synthesis from glucose, ammonium chloride and serine by washed suspensions of Escherichia coli 7-4 was inhibited by bacteriostatic concentrations of chloramphenicol and the tetracyclines (Aureomycin, Terramycin, and Achromycin). Indole synthesis was also inhibited by streptomycin but only by concentrations higher than those necessary for bacteriostasis. The inhibition by chloramphenicol and the tetracyclines does not appear to be due to inhibition of adaptive enzyme formation because these antibiotics still inhibited indole synthesis when added to suspensions which were forming indole at maximum rate. Streptomycin, in the same type of test, seemed to inhibit some adaptive process.

Indole synthesis by suspensions of antibiotic-resistant variants of Escherichia coli 7-4 was not inhibited by concentrations of antibiotics which inhibited synthesis by the parent strain. Suspensions of organisms resistant to high concentrations of streptomycin formed at least the same amount of indole in the presence of any concentration of streptomycin tested, as they did in its absence. Streptomycin often stimulated indole synthesis by such organisms. Suspensions of organisms which required streptomycin for growth, after growth in suboptimal concentrations of streptomycin, did not produce appreciable amounts of indole. The addition of streptomycin restored the activity in organisms grown in a liquid defined medium but did not do so with organisms grown on heart infusion agar. Streptomycinresistant and streptomycin-dependent strains resembled the parent strain in that they utilized malate + pyruvate, or oxalacetate, for indole formation in place of glucose. Strains resistant to various concentrations of chloramphenicol, Aureomycin and Terramycin showed a correlation between the amounts of antibiotic required to inhibit indole synthesis and to inhibit growth in a glucose + tryptophan + inorganic salts medium. The results indicate that some of the antibiotics interfere, either directly or indirectly, with indole synthesis.
\end{abstract}

Various workers have suggested that some antibiotics may interfere with the biosynthesis of the aromatic amino acids, the evidence being based on the ability of certain aromatic compounds to antagonize the inhibitory action of the antibiotics. Thus it has been suggested that chloramphenicol may interfere with the conversion of anthranilic acid to indole in Salmonella typhi (Truhaut, Lambin \& Boyer, 1951) and in Escherichia coli (Bergmann \& Sicher, 1952). Also Foster \& Pittillo (1953) found, again with $E$. coli, that tryptophan did not reverse chloramphenicol action although tyrosine and phenylalanine did. Bergmann, Sicher \& Volcani (1954), also on the basis of drug reversal tests with $E$. coli, suggested that Aureomycin and Terramycin interfere with the conversion of anthranilic acid to indole. The formation of aromatic compounds from simple precursors (glucose and ammonium ions) by washed suspensions of $E$. coli mutants has recently been described (Gibson, 
Jones \& Teltscher, $1955 a, 1956)$. These experiments have provided a system in which to test the effects of antibiotics on aromatic synthesis more directly. The formation of indole by substrains of $E$. coli 7-4 made resistant to streptomycin, chloramphenicol and the tetracyclines has been compared with that by the antibiotic-sensitive strain. Part of this work has already been briefly reported (Gibson, Jones \& Teltscher, 1955b).

\section{METHODS}

Preparation and use of suspensions of Escherichia coli. The methods used for the study of formation of indole by washed suspensions of Escherichia coli were described in detail by Gibson et al.(1956). Briefly, the organisms were harvested from $16 \mathrm{hr}$. cultures on heart infusion agar plates, washed twice in saline, and resuspended in $0.2 \mathrm{M}$-phosphate buffer $(\mathrm{pH} 7 \cdot 7$ ) to give the equivalent of about $1.5 \mathrm{mg}$. dry wt. organisms $/ \mathrm{ml}$., and used at once. The suspensions were then added to an equal volume of substrates and incubated at $37^{\circ}$. Indole formation was measured colorimetrically by using Ehrlich's reagent.

The organisms used were either Escherichia coli strain 7-4 (referred to as the parent strain), a mutant requiring tryptophan for growth, or antibioticresistant strains derived from the parent strain.

Basal synthesis system. Unless otherwise stated, the effects of the antibiotics were measured on the formation of indole in the following medium: glucose $(0.1 \mathrm{M}) ; \mathrm{NH}_{4} \mathrm{Cl}(0.005 \mathrm{M})$; DL-serine $(0.01 \mathrm{M})$ incubated at $37^{\circ}$ in $0.1 \mathrm{M}$-phosphate buffer $\mathrm{pH} \mathrm{7.7.} \mathrm{The} \mathrm{tests} \mathrm{were} \mathrm{carrled} \mathrm{out} \mathrm{in} \mathrm{a} \mathrm{final} \mathrm{volume} \mathrm{of} 5 \mathrm{ml}$. in $6 \times \frac{3}{4}$ in. tubes.

Antibiotics. The antibiotics used were Glaxo penicillin and streptomycin sulphate, Parke-Davis chloramphenicol, the hydrochlorides of Pfizer Terramycin (oxytetracycline), Lederle Aureomyrin (chlortetracycline) and Achromycin (tetracycline). The concentrations of streptomycin used are expressed in terms of free base. In experiments in which bacteriostatic tests were carried out in parallel with tests on indole formation the following procedures were adopted. Streptomycin was added to the tubes of the bacteriostatic test before autoclaving. Chloramphenicol was either autoclaved with the medium or a solution of $1000 \mu \mathrm{g} . / \mathrm{ml}$. was pasteurized at $70^{\circ}$ for $10 \mathrm{~min}$. and dilutions in sterile distilled water added aseptically to the tubes. The tetracyclines were prepared immediately before use and were pasteurized as above at $1 \mathrm{mg} . / \mathrm{ml}$. During earlier experiments, including some of those described by Gibson et al. $(1955 b)$, solutions of Aureomycin and Terramycin were prepared from capsules intended for oral administration. However, gifts of pure tetracyclines made it possible to use these for most of the work.

Bacteriostatic tests. These were carried out in the chemically defined medium described by Davis \& Mingioli (1950) with the addition of $10^{-4} \mathrm{M}-\mathrm{DL}$-tryptophan necessary for the growth of Escherichia coli 7-4. The glucose and tryptophan were added to the medium before autoclaving. Double-strength medium was tubed in $2.5 \mathrm{ml}$. volumes in $6 \times \frac{3}{4} \mathrm{in}$. acid-washed tubes; water and drug were added and the tubes autoclaved at $10 \mathrm{lb}$./sq.in. for $10 \mathrm{~min}$. Any further 
additions were made aseptically. The inoculum was one drop (about $0.03 \mathrm{ml}$.) of a light suspension (about $2 \times 10^{8} / \mathrm{ml}$.) of the organisms to be used. After, incubation for $24 \mathrm{hr}$. at $37^{\circ}$ the turbidity was measured with the E.E.L. portable colorimeter with $\frac{1}{4}$ in. diam. tubes and a 626 filter. The amount of growth was expressed in terms of scale reading; these two were directly proportional over the range used and a turbidity reading of 10 is equivalent to $0.3 \mathrm{mg}$. dry wt./ml.

Drug-resistant organisms. Drug-resistant substrains of Escherichia coli 7-4 were obtained either by direct selection from large populations or by serial subculture in increasing concentrations of the given antibiotic. Strains highly resistant to, or dependent on, streptomycin were isolated by washing off the growth from $24 \mathrm{hr}$. cultures on two heart infusion agar plates with the minimum amount of sterile distilled water and spreading the suspension over the surface of a heart infusion agar plate containing $400 \mu \mathrm{g}$. streptomycin $/ \mathrm{ml}$. Any colonies which appeared during incubation at $37^{\circ}$ for up to 4 days were subcultured and tested for resistance and dependence. Organisms showing a threeto fivefold increase in resistance were obtained by serial subculture of the parent strain in subinhibitory concentrations of streptomycin (Gibson \& Gibson, 1951).

Strains resistant to chloramphenicol and the tetracyclines were obtained from a series of bacteriostatic tests in defined medium, the inoculum for each new set of tubes being taken from the highest concentration of antibiotic which allowed visible growth in $24 \mathrm{hr}$.. Strains were sometimes obtained which had lost the ability to form indole. The reason for this is not known; such strains were discarded and a new series started from the parent strain.

Antibiotic-resistant strains were maintained on heart infusion agar slopes containing the appropriate antibiotic or, for strains resistant to high concentrations of streptomycin, on plain heart infusion agar slopes.

Preparation of suspensions of streptomycin-dependent organisms grown with minimal streptomycin. Streptomycin-deficient organisms were prepared by growing strains requiring streptomycin in suboptimal concentrations of streptomycin either on heart infusion agar plates or in a liquid synthetic medium.

Five ml. of the defined medium containing $20 \mu \mathrm{g}$. of streptomycin $/ \mathrm{ml}$. was inoculated with the dependent strain and incubated for $24 \mathrm{hr}$. at $37^{\circ}$. This culture $(0.2 \mathrm{ml}$.) was used as the inoculum for plates of heart infusion agar containing streptomycin which were then incubated for $20 \mathrm{hr}$. at $37^{\circ}$. The organisms were then harvested and washed in the usual way before use. Alternatively, Roux bottles containing $150 \mathrm{ml}$. of the defined medium + streptomycin were inoculated with $1 \mathrm{ml}$. of culture and incubated as above. Organisms were then spun down, washed twice with saline and resuspended in buffer.

Nomenclature of resistant strains. Strains resistant to, but not dependent on, streptomycin are referred to as SR, those resistant to chloramphenicol as CR and to Terramycin as TR. Strains which required streptomycin for growth are referred to as SD. 


\section{RESULTS}

\section{Antibiotics inhibiting indole synthesis by the parent strain}

The effects of antibiotics on indole formation are shown in Table 1. Penicillin when added at five times the bacteriostatic concentration (100 units $/ \mathrm{ml}$.) had no inhibitory effect and even at $1000 \mathrm{units} / \mathrm{ml}$. had a relatively small effect.

Table 1. The effects of antibiotics on indole synthesis and growth of the parent strain (Escherichia coli 7-4)

For indole synthesis washed organisms were incubated with basal synthesis system (glucose, $0.1 \mathrm{M} ; \mathrm{NH}_{4} \mathrm{Cl}, 0.005 \mathrm{M}$; DL-serine, $0.01 \mathrm{M}$; in $0.1 \mathrm{~m}$-phosphate buffer $\mathrm{pH} \mathrm{7.7}$ ) for $4 \frac{1}{2} \mathrm{hr}$. Bacteriostatic tests in minimal medium + tryptophan (see Methods). In this and all succeeding experiments shown, the amount of organisms used for indole synthesis was within the range $0 \cdot 65-0.80 \mathrm{mg}$. dry wt./ml. and the temperature of incubation was $37^{\circ}$.

\begin{tabular}{|c|c|c|c|c|}
\hline \multirow[b]{2}{*}{ Antibiotic } & \multicolumn{2}{|c|}{ Bacteriostatic tests } & \multicolumn{2}{|c|}{ Indole synthesis } \\
\hline & $\begin{array}{l}\text { Growth } \\
\text { in }\end{array}$ & $\begin{array}{c}\text { No } \\
\text { growth } \\
\text { in }\end{array}$ & $\begin{array}{l}\text { Conc. } \\
\text { antibiotic } \\
\text { added }\end{array}$ & $\begin{array}{c}\begin{array}{c}\text { Indole } \\
\text { formed }\end{array} \\
(\mathrm{m} \mu \mathrm{mole} / \mathrm{mg} .)\end{array}$ \\
\hline None & - & - & - & 276 \\
\hline Terramycin $(\mu \mathrm{g} . / \mathrm{ml})$. & $0 \cdot 25$ & 0.5 & 1 & 90 \\
\hline Aureomycin $(\mu \mathrm{g} . / \mathrm{ml})$. & $0 \cdot 25$ & 0.5 & 1 & 73 \\
\hline Achromycin ( $\mu \mathrm{g} . / \mathrm{ml})$. & $0 \cdot 25$ & 0.5 & 1 & 78 \\
\hline Chloramphenicol ( $\mu \mathrm{g} . / \mathrm{ml}$.) & 2 & $\mathbf{3}$ & $\mathbf{5}$ & 73 \\
\hline \multirow[t]{2}{*}{ Streptomycin $(\mu \mathrm{g} . / \mathrm{ml})}$. & $\mathbf{2}$ & $\mathbf{3}$ & 10 & 282 \\
\hline & & & 150 & 146 \\
\hline \multirow[t]{2}{*}{ Penicillin (units/ml.) } & 10 & 20 & 100 & 266 \\
\hline & & & 1000 & 255 \\
\hline
\end{tabular}

Chloramphenicol and the tetracyclines were found to inhibit indole synthesis markedly, even at about bacteriostatic concentrations.

Streptomycin at bacteriostatic concentration $(3 \mu \mathrm{g} . / \mathrm{ml}$.) did not inhibit the formation of indole but did so markedly at higher concentrations (150 $\mu \mathrm{g} . / \mathrm{ml}$.).

The results of more detailed experiments are presented below.

Chloramphenicol. There was a marked correlation between the concentrations inhibiting growth and those depressing indole formation. As can be seen from Fig. 1 a detectable inhibition of indole synthesis took place even at concentrations of the antibiotic below that required to inhibit growth completely.

Tetracyclines. The three tetracyclines all caused the same type of response as found with chloramphenicol. As an example, the results of an experiment with Achromycin are illustrated in Fig. 2. Once again indole synthesis was inhibited to some extent by antibiotic concentrations lower than those required for growth inhibition.

Streptomycin. The concentration of this antibiotic which completely inhibited growth had no appreciable effect on indole synthesis, though it was progressively inhibited at concentrations between 10 and $120 \mu \mathrm{g} . / \mathrm{ml}$. (Fig. 3). Above $120 \mu \mathrm{g} . / \mathrm{ml}$. there was only a slight increase in inhibition.

The effect of time of addition of antibiotics. The rate of indole synthesis increases during the first $2 \mathrm{hr}$. until a maximum rate is reached (Gibson et al. 
1956). The effect of adding antibiotics to cells producing indole at the maximum rate is shown in Fig. 4. Once again the action of streptomycin was found to differ distinctly from that of chloramphenicol and the tetracyclines. On the addition of either of the latter antibiotics indole synthesis was rapidly inhibited.

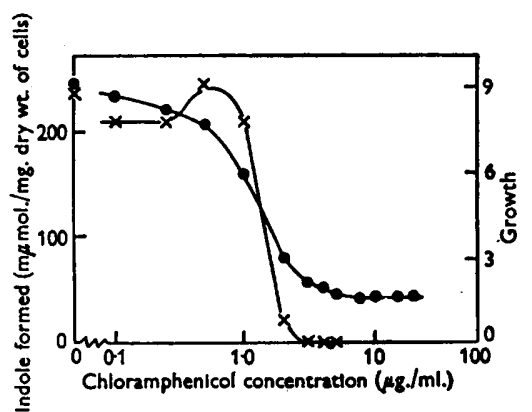

Fig. 1

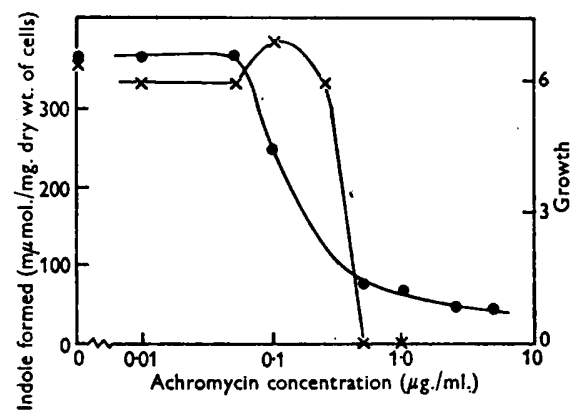

Fig. 2

Fig. 1. Effect of chloramphenicol on indole synthesis and growth. $-\times-\times-$ growth (see Methods); - indole synthesis after $4 \mathrm{hr}$. incubation.

Fig. 2. Effect of Achromycin on indole synthesis and growth. $-\times-\times-$, growth; , indole synthesis after $5 \mathrm{hr}$. incubation.

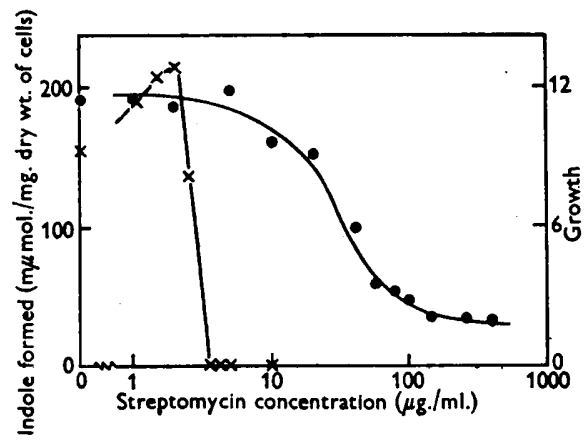

Fig. 3

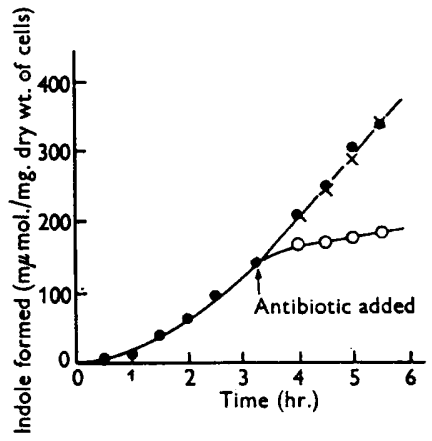

Fig. 4

Fig. 3. Effect of streptomycin on indole synthesis and growth. $-\times-\times-$, growth; , indole synthesis after $4 \mathrm{hr}$. incubation.

Fig. 4. The effect of antibiotics on cells forming indole at maximum rate. Organisms incubated initially in $80 \mathrm{ml}$. final volume. Immediately before addition of drugs, organisms and substrates were divided into $10 \mathrm{ml}$. lots; $0.1 \mathrm{ml}$. of each of the drugs added to give the final concentration shown below. $\longrightarrow$, no addition; $-\times-$ $150 \mu \mathrm{g}$. streptomycin $/ \mathrm{ml}$; _ $-\mathrm{O}-\mathrm{O}, 1 \mu \mathrm{g}$. Terramycin $/ \mathrm{ml}$. or $1 \mu \mathrm{g}$. Aureomycin $/ \mathrm{ml}$. or $5 \mu \mathrm{g}$. chloramphenicol $/ \mathrm{ml}$.

On the other hand, the addition of streptomycin at a concentration $(150 \mu \mathrm{g} . / \mathrm{ml}$. which would inhibit synthesis if added initially, did not affect the rate of synthesis. In some experiments in which the synthesis was observed for a longer time (e.g. $5 \mathrm{hr}$.) after the addition of streptomycin, some inhibition was observed. 


\section{Streptomycin-resistant cells}

Strains of Escherichia coli resistant to streptomycin fall into three groups (Umbreit, 1952), which are considered in turn.

A. Highly resistant organisms. Although with the parent strain streptomycin in concentrations greater than $10 \mu \mathrm{g} . / \mathrm{ml}$. inhibited indole formation, indole synthesis by the highly resistant strains was never inhibited by any concentration of streptomycin tested, up to $2000 \mu \mathrm{g} . / \mathrm{ml}$. On the contrary, indole synthesis was frequently stimulated (Fig. 5). Resistant strains usually, but not always,

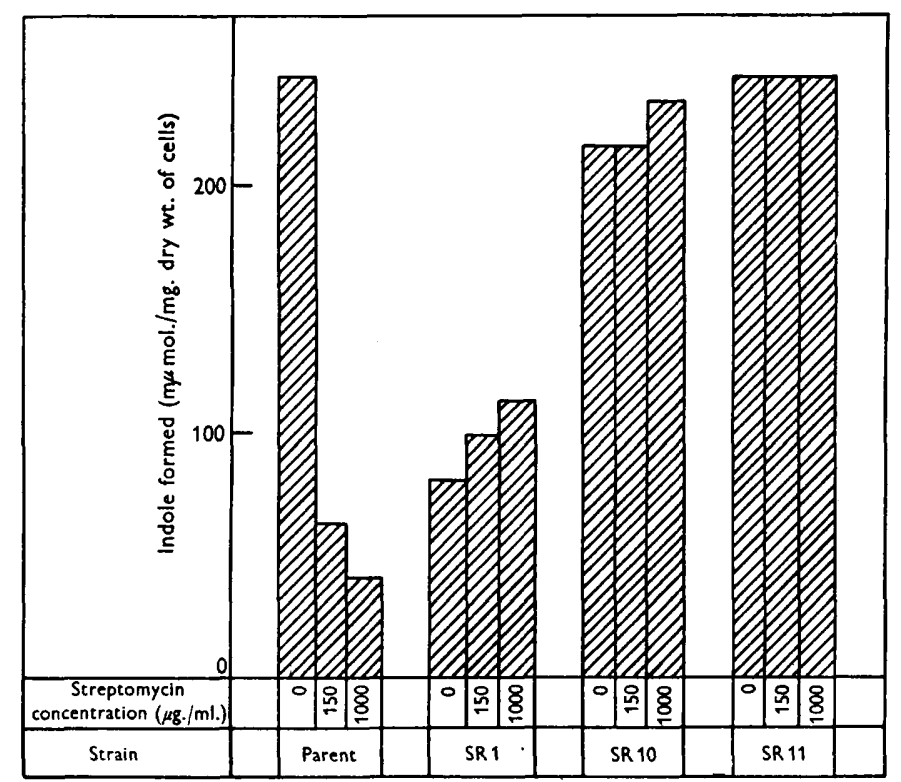

Fig. 5. Effect of streptomycin on indole synthesis by the parent strain and strains highly resistant to streptomycin. Cells incubated in basal synthesis system for $4 \frac{3}{4} \mathrm{hr}$., together with streptomycin as shown.

formed less indole than the parent strain. This loss of synthesizing power could be largely overcome by the addition of magnesium ions to the basal synthesis system (Table 2 ).

B. Organisms slightly resistant to streptomycin. An extensive investigation of indole synthesis by these organisms has not been carried out but the effect on it of streptomycin did not appear to differ significantly from that on indole synthesis by the parent strain.

C. Streptomycin-dependent organisms. Suspensions of a stiain which required streptomycin for growth, harvested from media containing $500 \mu \mathrm{g} . / \mathrm{ml}$. of streptomycin, formed indole in the presence of all concentrations of streptomycin tested. As with the highly resistant organisms, indole formation was often stimulated by streptomycin (Table 3 ).

However, SD organisms grown on the chemically defined medium containing suboptimal concentrations of streptomycin, failed to form appreciable 
amounts of indole in the absence of streptomycin. Similar organisms from heart infusion agar formed no appreciable indole even when streptomycin was added to the synthesis system (Table 3, Fig. 6). At the conclusion of experiments

Table 2. Streptomycin-resistant organisms: stimulation of indole synthesis

$$
\text { by magnesium }
$$

Suspensions were incubated with substrates for $4 \mathrm{hr}$.

$\begin{array}{ccc}\begin{array}{c}\text { Streptomycin- } \\ \text { resistant } \\ \text { strain }\end{array} & \begin{array}{c}\text { Basal } \\ \text { synthesis } \\ \text { system }\end{array} & \begin{array}{c}\text { Basal } \\ \text { synthesis } \\ \text { system } \\ \text { +MgSO_(10-4 }\end{array} \\ \text { SR1 } & 81 & 181 \\ \text { SR2 } & 195 & 278 \\ \text { SR3 } & 113 & 286 \\ \text { SR4 } & 127 & 233 \\ \text { SR5 } & 108 & 283 \\ \text { SR 6 } & 123 & 280\end{array}$

Table 3. Effect of streptomycin on indole synthesis by a streptomycin-dependent strain

Cells were incubated in basal synthesis system $+10^{-4} \mathrm{M}-\mathrm{MgSO}_{\text {, }}$ for $5 \mathrm{hr}$.

\begin{tabular}{|c|c|c|c|}
\hline \multicolumn{2}{|c|}{ Organisms grown on } & \multicolumn{2}{|c|}{ Indole synthesis (m $\mu$ mole/mg.) } \\
\hline Medium & $\begin{array}{l}\text { Streptomycin } \\
(\mu \mathrm{g} . / \mathrm{ml} .)\end{array}$ & $\begin{array}{l}\text { No added } \\
\text { streptomycin }\end{array}$ & $\begin{array}{l}\text { Streptomycin } \\
(1000 \mu \mathrm{g} . / \mathrm{ml} .)\end{array}$ \\
\hline Liquid defined & $\begin{array}{r}20 \\
500\end{array}$ & $\begin{array}{r}22 \\
205\end{array}$ & $\begin{array}{l}166 \\
206\end{array}$ \\
\hline Heart infusion agar & $\begin{array}{r}20 \\
500\end{array}$ & $\begin{array}{r}44 \\
338\end{array}$ & $\begin{array}{r}50 \\
\mathbf{3 7 7}\end{array}$ \\
\hline
\end{tabular}

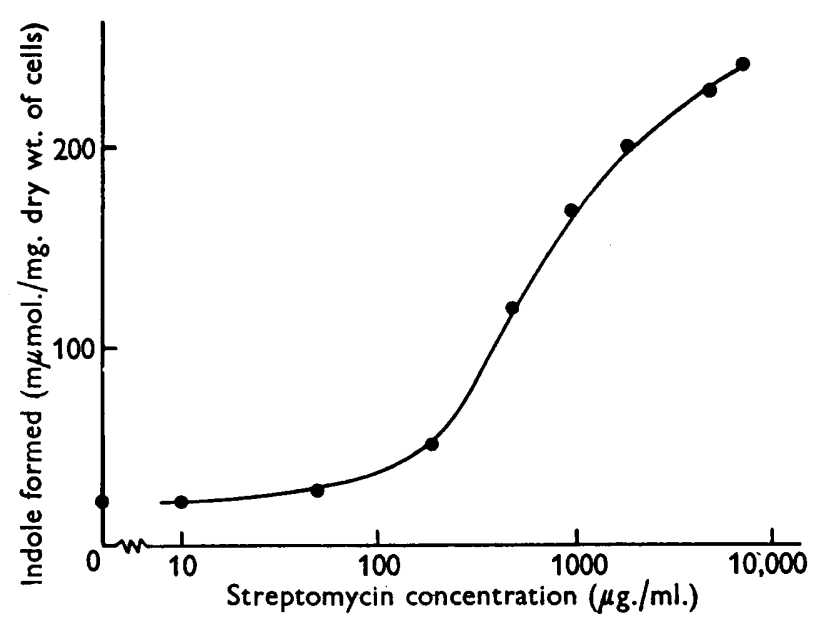

Fig. 6. Effect of streptomycin on indole synthesis by a streptomycin-dependent strain. Organisms harvested from defined liquid medium containing limiting streptomycin $\left(20 \mu \mathrm{g} . / \mathrm{ml}\right.$.). Basal indole svnthesis system $+\mathrm{MgSO}_{4}\left(10^{-4} \mathrm{M}\right)$ and streptomycin as shown. Incubation for $5 \mathrm{hr}$. 
with SD organisms the suspensions were plated to find out whether they still required streptomycin. While a few colonies did sometimes appear on medium containing no streptomycin, the bulk of the organisms still required streptomycin. There was no increase in the turbidity of the suspensions during the experiments.

The utilization of oxalacetate and pyruvate plus malate by resistant and dependent strains. The glucose in the basal synthesis system can be replaced by pyruvate plus malate but not by either alone (Teltscher \& Gibson, unpublished observations), or by oxalacetate. In view of the observations of Smith, Oginsky \& Umbreit (1949) concerning alterations in the metabolism of these compounds in streptomycin-resistant and -dependent organisms, it was of interest to compare their utilization for indole synthesis by the different strains. It was found (Table 4) that pyruvate plus malate, or oxalacetate, were utilized for indole formation by both the resistant and dependent strains tested.

Table 4. Utilization of malate plus pyruvate, and oxalacetate, by resistant and dependent strains

Organisms in 0.2 M-phosphate buffer pH 7.7 were incubated ( $4 \mathrm{hr}$. Expt. 1, $5 \mathrm{hr}$. Expt. 2) with substrates shown $+\mathrm{MgSO}_{4}\left(10^{-4} \mathrm{M}\right)$. Substrate concentrations; glucose, malate, pyruvate and oxalacetate $0.1 \mathrm{M}, \mathrm{NH}_{4} \mathrm{Cl} 0.005 \mathrm{M}$. Streptomycin-dependent cells grown on heart infusion agar containing $500 \mu \mathrm{g} . / \mathrm{ml}$. streptomycin.

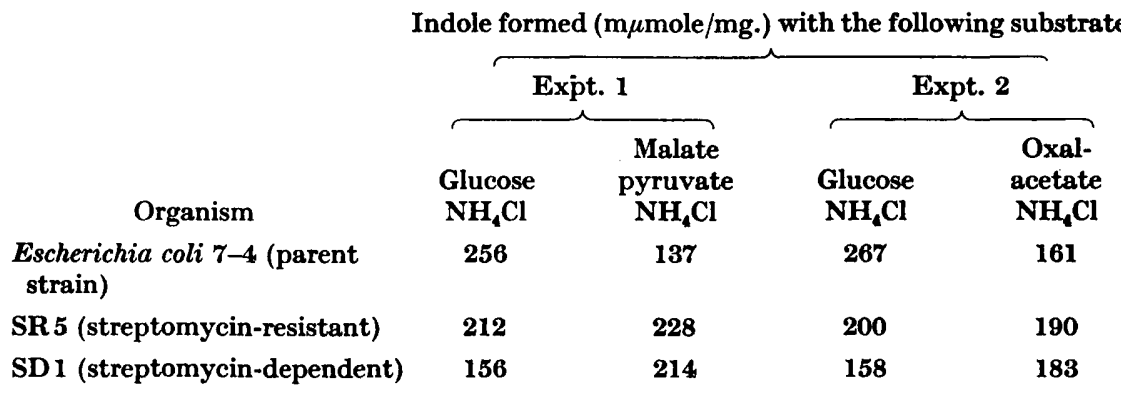

\section{Strains resistant to chloramphenicol}

The concentration of chloramphenicol needed to inhibit indole synthesis by suspensions of several resistant strains capable of growing in a concentration of about $100 \mu \mathrm{g}$. chloramphenicol $/ \mathrm{ml}$. was about the same as that needed to inhibit growth in the chemically defined medium. The result of a typical experiment is shown in Fig. 7.

\section{Strains resistant to the tetracyclines}

The effects of these antibiotics on indole synthesis and growth showed the same pattern as described above for chloramphenicol. The results shown in Fig. 8 indicate that even a relatively slight increase in resistance is paralleled by a similar effect on indole synthesis. A further example with cells resistant to a much higher concentration of Terramycin is shown below (Fig. 9). Similar results were obtained with strains resistant to Aureomycin. 


\section{Cross-resistance}

Organisms resistant to chloramphenicol, to Terramycin and to Aureomycin were tested to see if cross-resistance would be shown either in growth inhibitions or with regard to indole synthesis. No cross-resistance in either respect was demonstrate by organisms resistant to chloramphenicol. Organisms resistant

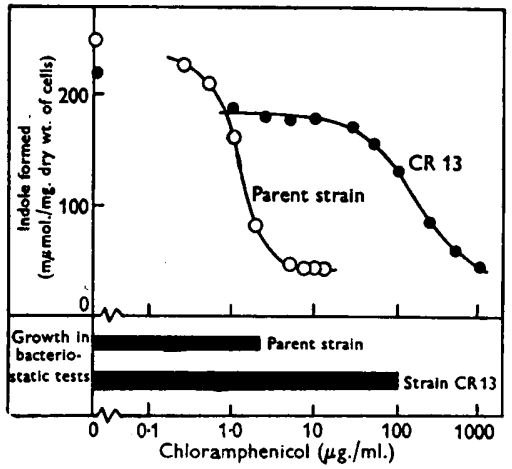

Fig. 7

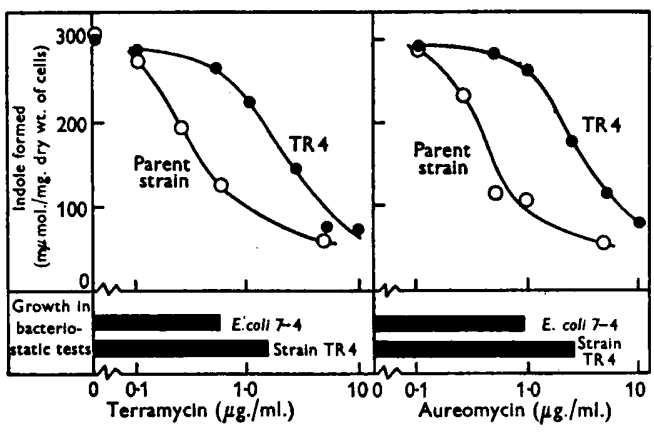

Fig. 8

Fig. 7. Effect of chloramphenicol on indole synthesis and growth by the parent strain and a strain (CR 13) resistant to chloramphenicol. Indole synthesis: suspensions incubated in basal synthesis system with concentrations of chloramphenicol as shown for $4 \mathrm{hr}$. Bacteriostatic tests : $24 \mathrm{hr}$. in defined medium (see Text). Horizontal bars represent growth in the concentration of chloramphenicol shown.

Fig. 8. The effects of Terramycin and Aureomycin on the parent strain and a Terramycinresistant strain (TR4). Data as for Fig. 4 except in indole synthesis : parent strain $4 \mathrm{hr}$. incubation; strain TR $45 \mathrm{hr}$. incubation.

Table 5. Cross-resistance in bacteriostatic tests: increased resistance to Achromycin, Aureomycin and chloramphenicol of strain (TR13) resistant to Terramycin

$\quad$ Antibiotic
Achromycin
Terramycin
Aureomycin
Chloramphenicol

\begin{tabular}{|c|c|}
\hline \multicolumn{2}{|c|}{$\begin{array}{l}\text { Highest conc. }(\mu \mathrm{g} . / \mathrm{ml} .) \\
\text { allowing growth }\end{array}$} \\
\hline $\begin{array}{c}\text { Parent } \\
\text { strain }\end{array}$ & $\begin{array}{l}\text { Strain } \\
\text { TR 13 }\end{array}$ \\
\hline 0.25 & 20 \\
\hline 0.25 & 20 \\
\hline 0.5 & 20 \\
\hline 2 & $\mathbf{5 0}$ \\
\hline
\end{tabular}

to Terramycin or Aureomycin were not only resistant to the other tetracyclines but also to chloramphenicol (Table 5 and Figs. 8 and 9). Fig. 8 shows that this held good with organisms only slightly resistant to Terramycin. The effects of antibiotics on indole synthesis by organisms more highly resistant to Terramycin (Table 5) are shown in Fig. 9. Indole synthesis by these resistant cells was much less inhibited by the other tetracyclines and by chloramphenicol than synthesis by the parent strain. 


\section{DISCUSSION}

Studies on the action of the tetracyclines and chloramphenicol on biochemical reactions using cell suspensions or extracts have usually shown either no inhibition, or inhibition at concentrations higher than bacteriostatic. However, exceptions have been shown (Gale \& Folkes, 1953; Saz \& Marmur, 1953; Wisseman, Smadel, Hahn \& Hopps, 1954 ; Hahn \& Wisseman, 1951). Chloramphenicol, Aureomycin and Terramycin were found by Hahn \& Wisseman (1951) to inhibit adaptive enzyme formation in suspensions of Escherichia coli. In the present experiments these antibiotics, when added at bacteriostatic
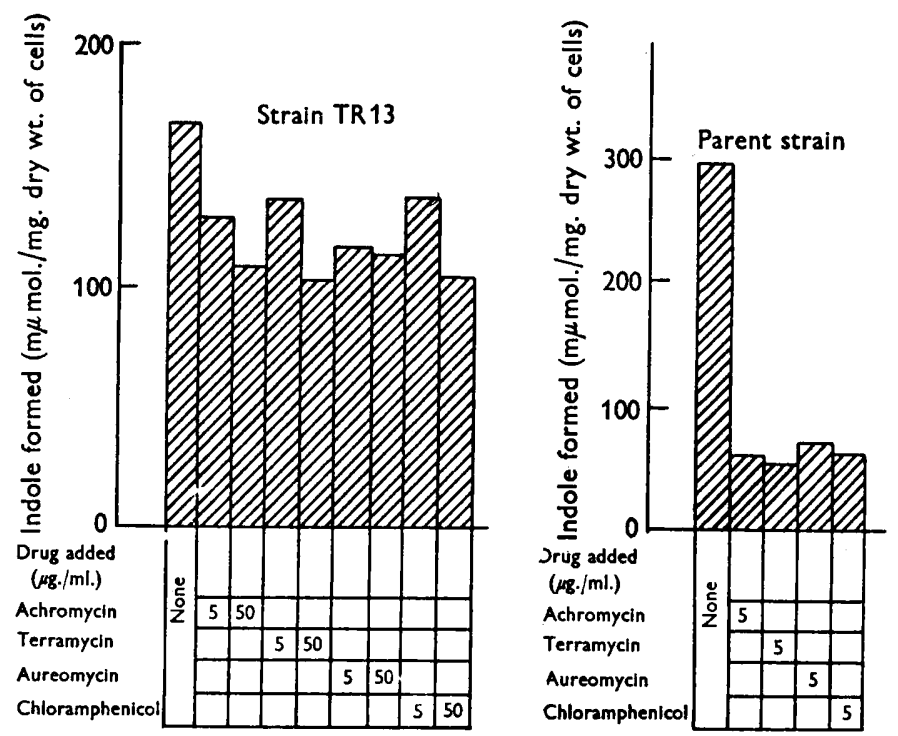

Fig. 9. Effect of antibiotics on indole synthesis by the parent strain and a strain (TR 13) resistant to Terramycin. Details as for Fig. 3. Incubation for $5 \mathrm{hr}$.

concentrations, inhibit the synthesis of indole from glucose, ammonium chloride and serine by suspensions of $\boldsymbol{E}$. coli. Although the rate of indole synthesis is typical of an adaptive process (Gibson et al. 1956) it does not seem that either chloramphenicol or the tetracyclines are interfering with adaptive enzyme formation alone, in this case, since the addition of antibiotic while indole synthesis is proceeding at maximum rate still causes inhibition.

That the tetracyclines and chloramphenicol may inhibit the same or related reactions is supported by the observation that cross-resistance can develop between these antibiotics (Herrel, Heilman \& Wellman, 1950; Pansy, Khan, Pagano \& Donovick, 1950).

The questions as to which stage or stages in aromatic synthesis are inhibited by these antibiotics, and whether their action is directly on reactions in the synthetic pathway, have yet to be answered. The fact that not only tryptophan, but several of the other aromatic amino acids, have some action in

G. Microb. $\mathrm{xv}$ 
antagonizing the action of chloramphenicol (Bergmann et al. 1954; Foster \& Pittillo, 1953; Woolley, 1950; Truhaut et al. 1951) suggests that this drug may well interfere with some reaction common to the synthesis of these amino acids. Preliminary experiments with washed suspensions of a strain of Escherichia coli which forms anthranilic acid indicate that anthranilic acid synthesis is also inhibited by Terramycin and chloramphenicol.

Streptomycin at bacteriostatic concentrations does not inhibit indole synthesis. Therefore it seems likely that its effect on aromatic synthesis is not the primary cause of bacteriostasis. However, the process which is inhibited by the higher concentrations is presumably of importance during the development of resistance to high levels of streptomycin. Streptomycin appears to inhibit some process which is adaptive since the addition of the antibiotic, once the cells are forming indole at their maximum rate, no longer has any immediate effect. Whether the process inhibited is actually that of adaptive enzyme formation is still an open question.

Comparison of the effects of the antibiotics on indole synthesis by the parent and drug-resistant strains shows that indole synthesis by the resistant strains is much less susceptible to the action of the corresponding antibiotic.

Although it seems likely that the reactions inhibited by low concentrations of streptomycin may not be directly concerned with aromatic synthesis, for cells to become highly resistant the reactions (reflected here by indole synthesis) inhibited by higher concentrations of streptomycin must become insusceptible to the drug in some way or replaced by an alternative metabolic pathway.

Oxygen uptake in the presence of pyruvate plus oxalacetate by aged suspensions of Escherichia coli was found by Oginsky, Smith \& Umbreit (1949) to be inhibited by low concentrations of streptomycin. It was suggested that streptomycin inhibited some metabolic pathway involving a pyruvateoxalacetate condensation. Strains which were resistant to, or dependent on, streptomycin were found to have lost the ability to oxidize pyruvate plus oxalacetate, and it was suggested that such cells had developed an alternative metabolic pathway (Smith et al. 1949). In the present experiments it has been found that oxalacetate, or malate plus pyruvate, will serve as substrates for indole synthesis not only with $E$. coli 7-4, but also with the streptomycin-resistant and dependent substrains. With the fresh organisms used pyruvate would be produced from oxalacetate (Oginsky et al. 1949). If an oxalacetate-pyruvate condensation takes place during indole synthesis under the conditions used, the resistant and dependent organisms apparently still retain the ability to carry out the reaction. The results obtained with streptomycin during the present work indicating that it may inhibit some adaptive process are similar to those of Roote \& Polglase (1955) who tested the effects of dihydrostreptomycin on the formation of adaptive enzymes by suspensions of $E$. coli. These workers found that the formation of adaptive enzymes for the oxidation of certain carbohydrates was inhibited by $1000 \mu \mathrm{g}$. dihydrostreptomycin $/ \mathrm{ml}$. The same concentration did not significantly inhibit the formation of adaptive enzymes in resistant organisms and stimulated their formation slightly in dependent organisms; those deficient in streptomycin were not tested. 
Organisms dependent on streptomycin for growth could apparently be made streptomycin-deficient by growing them in a medium containing suboptimal concentrations of streptomycin. Suspensions of such organisms prepared from a liquid defined medium had largely lost the power to form indole, the activity being restored by the inclusion of streptomycin among the substrates for indole synthesis. Such results, if compared with studies on the function of growth factors, are consistent with the view that in organisms requiring streptomycin for growth the antibiotic may act as a co-enzyme in some vital reaction. It is of interest that indole synthesis by suspensions of streptomycinresistant organisms was often stimulated by streptomycin. Streptomycindeficient organisms harvested from heart infusion agar formed very little indole but in this case the activity could not be restored by the addition of streptomycin.

In the case of organisms resistant to chloramphenicol and tetracyclines, the correlation between the minimal bacteriostatic concentration and the amount of antibiotic required to inhibit indole synthesis supports the view that these antibiotics inhibit vital reactions concerned in aromatic synthesis.

Strains of Escherichia coli made resistant to either chloramphenicol, Terramycine or Aureomycin have been found to show a cross-resistance to the other two drugs (Herrel et al. 1950; Pansy et al. 1950). During the present experiments strains resistant to chloramphenicol were not found to show any crossresistance. However, strains cultivated in the presence of either Aureomycin or Terramycin showed a cross-resistance not only to the other tetracyclines but also to chloramphenicol. This cross-resistance was shown by growing organisms and by indole synthesis in suspensions. The present evidence does not provide any answer as to the way in which the resistant organisms are able to carry out biochemical processes in the presence of concentrations of antibiotics which inhibit the same processes in sensitive organisms. The study of aromatic synthesis provides an experimental approach in this problem. The results presented suggest that several antibiotics interfere with reactions associated with aromatic synthesis and that examination of these reactions may be of use in studying their mode of action.

We wish to thank Mr G. Morrison for technical assistance and Dr Margaret Gibson for her advice. We are grateful to Professor S. D. Rubbo for his encouragement of this work and to the National Health and Medical Research Council for a grant.

We are indebted to Dr C. I. Jarowski of Chas. Pfizer and Co. Inc., for a gift of crystalline Terramycin hydrochloride and Dr B. L. Hutchings of the Lederle Laboratories for gifts of Aureomycin and Achromycin hydrochlorides.

\section{REFERENCES}

Bergmann, E. D. \& Sicher, S. (1952). Mode of action of chloramphenicol. Nature, Lond. 170, 931.

Bergmann, E. D., Sicher, S. \& Volcani, B. E. (1954). The action of Chloromycetin, Aureomycin and Terramycin on the biosynthesis of indole in Escherichia coli. Bull. Res. Coun. Israel, 4, 19. 


\section{F. Gibson and others}

Davis, B. D. \& Mrngroli, E. (1950). Mutants of Escherichia coli requiring methionine or vitamin $B_{12}$. J. Bact. 60, 17.

Foster, J. W. \& Pitrillo, R. F. (1953). Metabolite reversal of antibiotic inhibition, especially reversal of Aureomycin inhibition by riboflavin. J. Bact. 66, 478.

Gale, E. F. \& Folkes, J. P. (1953). The assimilation of amino acids by bacteria. 15. Actions of antibiotics on nucleic acid and protein synthesis in Staphylococcus aureus. Biochem. J. 53, 493.

Grison, M. I. \& Gibson, F. (1951). Development of resistance to dihydrostreptomycin by Bacterium coli. Nature, Lond. 167, 113.

Gibson, F., Jones, M. J. \& Teltscher, H. (1955 $a$ ). Synthesis of indole and anthranilic acid by mutants of Escherichia coli. Nature, Lond. 175, 853.

Gibson, F., Jones, M. J. \& Teltscher, H. (1955b). Effect of antibiotics on indole synthesis by Escherichia coli 7-4. Nature, Lond. 176, 164.

Gibson, F., Jones, M. J. \& Teltscher, H. (1956). The synthesis of indole by washed cell suspensions of Escherichia coli. Biochem. J. 64, 132.

Hahn, F. E. \& Wisseman, C. L. (1951). Inhibition of adaptive enzyme formation by antimicrobial agents. Proc. Soc. exp. Biol., N.Y. 76, 533.

Herrel, W. E., Heilman, F. R. \& Wellman, W. E. (1950). Some bacteriologic, pharmacologic and clinical observations on Terramycin. Ann. N.Y. Acad. Sci. $53,448$.

Oginsky, E. L., Smith, P. H. \& Umbreit, W. W. (1949). The action of streptomycin. I. The nature of the reaction inhibited. J. Bact. 58, 747.

Pansy, F. E., Khan, P., Pagano, J. F. \& Donovick, R. (1950). The relationship between Aureomycin, chloramphenicol and Terramycin. Proc. Soc. exp. Biol., N.Y. 75, 618.

Roote, S. M. \& Polglase, W. J. (1955). The effect of dihydrostreptomycin on the formation of adaptive enzymes by a strain of Escherichia coli. Canad. J. Biochem. Physiol. 33, 792.

Saz, A. K. \& Marmur, J. (1953). The inhibition of organic nitro-reductase by Aureomycin in cell-free extracts. Proc. Soc. exp. Biol., N.Y. 82, 783.

Smith, P. H., OGinsky, E. L. \& Umbreit, W. W. (1949). The action of streptomycin. II. The metabolic properties of resistant and dependent strains. J. Bact. 58, 761 .

Truhaut, R., Lambin, S. \& Boyer, M. (1951). Contribution a l'étude du mécanisme d'action de la chloromycétine vis-à-vis d'Eberthella typhi role du tryptophane. Bull. Soc. Chim. biol., Paris, 33, 387.

Umbreit, W. W. (1952). The mode of action of streptomycin in Symposium sur le Mode d'Action des Antibiotiques, p. 63. Paris: Sedes.

Wisseman, C. L., Smadel, J. E., Hahn, F. E. \& Hopps, H. E. (1954). Mode of action of chloramphenicol. I. Action of chloramphenicol on assimilation of ammonia and on synthesis of proteins and nucleic acids in Escherichia coli. J. Bact. 67, 662.

Woolley, D. W. (1950). A study of non-competitive antagonism with Chloromycetin and related analogues of phenylalanine. J. biol. Chem. 185, 293.

(Received 3 April 1956) 